\title{
Carbon emission reduction technologies in China
}

\author{
Xintong Zhang ${ }^{1, \mathrm{a}, *, \dagger}$, Longshan $\mathrm{Fu}^{2, \mathrm{~b}, *, \dagger}$ and Yu Huang ${ }^{3, \mathrm{c}, *},{ }^{*}$ \\ ${ }^{1}$ Division of Science and Technology, Beijing Normal University-Hong Kong Baptist University United International College, Zhuhai \\ 519087, China; \\ ${ }^{2}$ Division of Science and Technology, Beijing Normal University-Hong Kong Baptist University United International College, Zhuhai \\ 519087, China; \\ ${ }^{3}$ School of Energy and Mechanical Engineering, Nanjing Normal University, Nanjing 210046, China; \\ ${ }^{\dagger}$ These authors contributed equally.
}

\begin{abstract}
Environmental pollution is mainly caused by carbon emissions, so carbon emission reduction is our top priority now. Carbon-containing greenhouse gas emissions mainly come from the following aspects: (1) fossil fuel combustion; (2) leakage and volatilization in the process of fuel extraction, processing, transportation, and industrial utilization; (3) traditional biomass fuel combustion. The greenhouse effect will cause an increase in temperature, the rise of sea level, and the reduction of biodiversity. Due to little or no carbon emissions, new energy is a current research direction. It mainly includes wind energy, solar energy, hydropower, nuclear energy, and biological energy. Among them, wind power technology is quite mature, and the cost of wind power has become competitive in the market. Solar energy is an inexhaustible, nonpolluting, renewable, and clean energy source, which is gradually entering the stage of large-scale development. Hydropower is clean energy, renewable, pollution-free, and low operating costs. Nuclear energy is characterized by high efficiency and low carbon, coming from the fission energy released by the fission reaction of the fissionable material (nuclear fuel) in the nuclear reactor. Biomass resources can be divided into four categories: forest resources, crop straws, poultry manure, and household garbage, and its biggest feature is its renewability. Besides, carbon capture and carbon storage are other ways to reduce carbon emissions. Carbon capture uses chemical adsorption, physical adsorption, adsorption separation, and membrane separation to capture carbon dioxide. Carbon storage injects supercritical $\mathrm{CO} 2$ into a closed geological structure containing oil, gas, water, or non-commercial coal seams through pipeline technology to form long-term or permanent $\mathrm{CO} 2$ storage
\end{abstract}

\section{Introduction}

The greenhouse effect increases the earth's surface temperature caused by the release of a large amount of $\mathrm{CO} 2$ and nitrous oxide into the atmosphere. It generally results in a rise in sea level, destruction of coastal cities and ecological balance, an increase in the spread of diseases, great climate change, etc. Therefore, strengthening the research on the greenhouse effect and adopting corresponding countermeasures have practical significance.

$\mathrm{CO} 2$ emissions are the root causes of these environmental issues. Thus, reducing $\mathrm{CO} 2$ emissions is the focus of China's energy strategy development. Identifying the main drivers of the industry's $\mathrm{CO} 2$ emissions and reducing carbon emissions are vital for China's emission reduction and environmental protection.

This article reviews the means of reducing carbon emissions. Research is carried out from the following aspects: (1) Carbon sources and impacts; (2) The principles, advantages, disadvantages, and prospects of new energy sources, including wind energy, solar energy, hydropower, nuclear energy, and biomass energy; (3) Carbon capture and carbon sequestration.

\section{Carbon}

\subsection{Carbon source}

$\mathrm{CO} 2$ is the most important source of greenhouse gases, which mainly comes from the following aspects: (1) Fossil fuel combustion; (2) Leakage and volatilization during fuel extraction, processing, transportation, and industrial utilization; (3) Combustion of traditional biomass fuels. Among them, fossil fuel combustion mainly includes energy consumption in the energy industry, power industry, district heating, other energy and conversion industries, and energy consumption in the process of industrial production [1] (Table 1).

In addition to the burning of fossil fuels, the mining, processing, and transportation of coal, oil, and natural gas are also accompanied by a large amount of direct

*an830004041@mail.uic.edu.cn, bn830004003@mail.uic.edu.cn, c20190429@njnu.edu.cn. 
emissions of greenhouse gases. At the same time, the combustion of crop straw, fuelwood, and other biomass fuels and the burning of agricultural waste and wasteland are also the main energy sources of greenhouse gases.
From a global perspective, biomass combustion contributes to $\mathrm{CO} 2$ and $\mathrm{CH} 4$ emissions is about $40 \%$ and $10 \%$, respectively [2].

Table 1. Carbon emission coefficient [3]

\begin{tabular}{|c|c|c|c|c|c|}
\hline Energy name & $\begin{array}{c}\text { Average unit } \\
\text { heat, } \mathbf{k J} / \mathbf{k g}\end{array}$ & $\begin{array}{c}\text { Standard coal } \\
\text { factor, kgce/kg }\end{array}$ & $\begin{array}{c}\text { Carbon content per } \\
\text { calorific value (ton } \\
\text { carbon/TJ) }\end{array}$ & $\begin{array}{c}\text { Carbon } \\
\text { oxidation } \\
\text { rate }\end{array}$ & $\begin{array}{c}\mathbf{C O 2} \text { emission } \\
\text { factor, } \mathbf{~ k g} \cdot \mathbf{C O 2} / \mathbf{k g}\end{array}$ \\
\hline raw coal & 20908 & 0.7143 & 26.37 & 0.94 & 1.9003 \\
\hline Coke & 28435 & 0.9714 & 29.5 & 0.93 & 2.8604 \\
\hline crude & 41816 & 1.4286 & 20.1 & 0.98 & 3.0202 \\
\hline Fuel oil & 41816 & 1.4286 & 21.1 & 0.98 & 3.1705 \\
\hline gasoline & 43070 & 1.4714 & 18.9 & 0.98 & 2.9251 \\
\hline kerosene & 43070 & 1.4714 & 19.5 & 0.98 & 3.0179 \\
\hline Diesel oil & 42652 & 1.4571 & 20.2 & 0.98 & 3.0959 \\
\hline liquefied petroleum gas & 50179 & 1.7143 & 17.2 & 0.98 & 3.1013 \\
\hline Refinery dry gas & 46055 & 1.5714 & 18.2 & 0.98 & 3.0119 \\
\hline Oilfield natural gas & $38931 \mathrm{~kJ} / \mathrm{m} 3$ & $1.330 \mathrm{kgce} / \mathrm{m} 3$ & 15.3 & 0.99 & $2.1622 \mathrm{~kg}-\mathrm{CO} 2 / \mathrm{m} 3$ \\
\hline
\end{tabular}

\subsection{Carbon impact}

\subsubsection{Leading to global warming}

The impact of climate warming on the forestry and animal husbandry environment is manifold. Increasing $\mathrm{CO} 2$ concentration would increase the photosynthesis of natural vegetation, temperature, growth period, and vegetation yield. If low-quality grasses can better adapt to the changing environment and quickly occupy the grasslands, the grasslands' productivity will be greatly reduced; If the temperature rises, the possibility of fires will increase.

With climate warming, the atmospheric environment =and global precipitation will also change. The evaporation would increase, the moisture content in the atmosphere would increase, and thus the precipitation would increase to a certain extent. Global warming would cause uneven distribution of precipitation in various regions, and even in some regions, precipitation may decrease, leading to aggravation of drought and accelerating the process of desertification.

Also, global warming has the following two effects on the ocean: the water temperature of the mixed layer of the ocean is raised, and the thermal expansion caused by the warming can significantly cause the sea level to rise; the rise in temperature and sea temperature could cause a large amount of melting of the polar ice caps, and the melted ice caps would enter the ocean, causing sea-level rise.

\subsubsection{Harm to human health and species diversity}

Global temperature warms would also increase disease rates in high-latitude countries. According to statistics, the temperature rises by 2 to 4 degrees. If there are no other environmental changes, the population mortality rate will increase. Besides, global warming also has an impact on some species on the earth. Some species may not adapt to this climate change, resulting in a decrease in species diversity.

\section{New Energy}

\subsection{Wind energy}

\subsubsection{Principles of wind power generation}

Wind power includes two energy conversion processes: from wind energy to mechanical energy and mechanical energy to electrical energy. It can be divided into three modes. One is the independent operation mode. Usually, a small wind turbine provides electricity to one or several households, and it uses storage batteries to ensure electricity consumption when there is no wind. The second is the combination of wind power and other power generation methods (such as diesel power generation) to supply power to facilities. Third, wind power generation is integrated into the conventional power grid to provide power to the large power grid; often, dozens or even hundreds of wind generators are installed in one wind farm, which is the main development direction of wind power generation.

At present, domestic wind power generation systems use asynchronous generators to directly connect to the grid. Changes in wind speed will cause changes in the wind generators' active and reactive power injected into the grid, which will cause fluctuations in the nearby grid bus voltage. To overcome this shortcoming, AC-excited generators can be used in wind power systems to have better dynamic and static characteristics [4].

\subsubsection{Advantages}

Wind power has the irreplaceable advantages and competitiveness of other energy sources. The total 
potential of wind power generation in China is as high as 250 million $\mathrm{kW}$. The advantages of wind power can be summarized as follows:

(1) The cost of constructing wind farms is low, which is much lower than that of hydropower plants, thermal power plants, and nuclear power plants;

(2) Wind power is a clean natural energy source without environmental pollution problems.

(3) Compared with other power generation methods, wind power generation generally has a short construction period (the wind turbine's installation time is not more than 3 months). The construction period of a $500,000 \mathrm{~kW}$ wind farm is less than 1 year, and the installed capacity is flexible

(4) Wind power generation is simple to operate and can be completely unattended.

(5) Wind power generation occupies a small area. Buildings such as generator sets, monitoring, and power transformation only occupy about $7 \%$ of the wind power plant's land, and other industries can still use the remaining sites. The terrain requirements are low, and it can be constructed in hills, seasides, riverbanks, deserts, and other places [5].

\subsubsection{Disadvantages}

(1) Disturb the birds

(2) The wind speed is unstable, and the energy produced is unstable

(3) Wind energy utilization is severely restricted by geographical location

(4) Low conversion efficiency of wind energy

(5) Wind energy is a new type of energy, and the related equipments are not completed [6].

\subsubsection{Development prospects of wind energy in China}

(1)Natural wind energy

At present, c The cost of wind power in foreign countries has dropped to a little higher than that of thermal power generation, and it is still declining. From 2020 to 2050 , if the annual average increase rate is about $10 \%$ in China, the installed capacity of wind power can be expected to increase from 100 million $\mathrm{kW}$ to about 1.6 billion $\mathrm{kW}$.

(2)Industrial wind energy

As we all know, industrial energy consumption is a big energy consumer in the national economy. Still, a considerable part of the energy is wasted unknowingly in the process, and the energy in industrial exhaust air accounts for a considerable proportion. If considering making full use of this part of the energy, it will be another good way for wind energy utilization. Compared with natural wind power generation, industrial wind power generation has the following advantages:

a. Industrial wind energy facilities are generally concentrated in cities, where there is a relatively large electricity demand, so there is no electricity transportation problem. In addition, excess electricity can be directly transmitted through the urban power grid. b. The airflow of industrial exhaust air is relatively regular compared to natural wind, so it is more convenient to use.

c. Industrial wind energy also meets the purpose of energy-saving and efficiency enhancement of enterprises, thereby promoting sustainable energy development in my country [7].

\subsection{Solar energy}

Solar energy is an inexhaustible, non-polluting, renewable, and clean energy source. The total amount of solar energy resources is huge, and its radiation can last hundreds of billions of years. Even if the energy radiated by the sun to the earth is only billions of times the total radiant energy, compared to humans, the energy radiated by the sun can reach millions of tons of coal per second.

\subsubsection{Principles of Solar Power Technology}

At present, there are two power generation methods for solar power generation: one is to convert solar energy into thermal energy and then generate electricity in a conventional way, which is called solar thermal power generation. The other is to use photovoltaic devices to directly convert solar energy into electrical energy using photovoltaics.

\subsubsection{Advantages of solar power}

(1) The sunlight is abundant, common, and easy to get. It has the characteristics of direct acquisition, collection, development, and use, and it is not restricted by region, from ocean land to mountain basin. Compared with fossil fuels, solar energy saves a lot of manpower and financial resources without the need for mining and transportation.

(2) The use of solar energy is safe and hygienic. It is a purely physical process because it does not produce any pollutants and greenhouse gas emissions. There is no environmental pollution problem, and it is far safer than nuclear energy. Only photovoltaic power generation equipment uses conventional energy in the manufacturing process and has $\mathrm{CO} 2$ emissions. The $\mathrm{CO} 2$ emissions of photovoltaic power generation can be calculated by the energy recovery time. With the development and progress of technology, the energy recovery time of photovoltaic systems is getting shorter.

(3) The total solar radiant energy is very high. The energy irradiated to the earth per second is equivalent to burning 5 million tons of coal. The energy is about burning 130 trillion tons of coal, about $2 \times 104$ times the current global energy consumption [8].

\subsubsection{Disadvantages of solar power}

(1) Dispersibility

Although the total amount of solar radiation energy reaching the earth's surface is very large, the energy flux density on the ground is very low. Therefore, when using solar energy to obtain a certain conversion power, a set of 
collection and conversion equipment with a considerable area is often required, which is relatively expensive.

(2) Discontinuity and instability

Solar radiant energy not only changes regularly with factors such as day and night, seasons, latitude, and altitude, but is also affected by random changes in weather such as sunny, overcast, rainy, and cloud, which makes large-scale applications of solar energy more difficult.

(3) Low efficiency and high cost.

Although the current solar energy utilization is theoretically feasible in some aspects and the technology is relatively mature, its equipment operation efficiency is low, and the cost is high, so the economy still cannot compete with conventional energy. The future development of solar energy is also mainly affected by economic constraints [9].

(4) Solar panel pollution

Solar panels have a certain life span. Generally, solar panels need to be replaced once at most 3-5 years, and the replaced solar panels are very difficult to be decomposed by nature, causing considerable pollution.

\subsubsection{Rationality}

The global solar power generation is gradually entering the stage of large-scale development. China is rich in solar resources, and the solar power industry has a broad prospect. Thus it is becoming the most promising market for solar power generation in the world. In recent years, solar power generation technology has made great progress: the economy has improved significantly, the use of solar energy has increased, and the output has increased sharply. From the perspective of global solar energy utilization, although the solar energy utilization rate accounts for a small proportion of the total energy utilization, there are problems such as storage difficulties, low efficiency, and a large investment. In the long run, investment and development of solar energy will continue to increase. Governments of China regard solar energy as an important part of the national new energy development strategy. This will help change the traditional energy structure, overcome energy tension, curb global warming, improve the ecological environment and achieve green environmental protection. In conclusion, solar energy resources will play a very important role in human life and economic development and become an indispensable and important energy source for mankind [10].

\subsection{Hydropower energy}

Water energy is a kind of clean and green energy. It refers to energy resources such as kinetic, potential, and pressure energy of water bodies. Hydropower is a kind of renewable energy, which is mainly used for hydroelectric power generation. Hydroelectric power converts the potential and kinetic energy of water into electrical energy.

\subsubsection{Principle of hydropower}

Due to the water drop's gravitational potential energy, the water wheel can be continuously pushed to generate electricity. It means that the process is that the water's potential energy is from the mechanical energy, and then the mechanical energy turns the generator to generate electricity.

\subsubsection{Advantages of hydropower}

(1) Replace coal-fired power generation and reduce pollution

China's current installed hydropower capacity has exceeded $1.0 \times 108 \mathrm{~kW}$, and it is estimated to reach $2.5 \times$ $108 \mathrm{~kW}$ in 2020. Calculated on an average annual utilization hour of $4,000 \mathrm{~h}$, the power generation capacity is $10000 \times 108 \mathrm{~kW} \cdot \mathrm{h}$, which is equivalent to about $5 \times$ 108 The amount of electricity generated from raw coal can reduce emissions of $\mathrm{CO} 29.26 \times 108 \mathrm{t}$, SO2 $631 \times 104 \mathrm{t}$, $\mathrm{NO} 2,252 \times 104 \mathrm{t}$, and soot $227 \times 104 \mathrm{t}$. The development and utilization of water energy resources can reduce air pollution and the greenhouse effect, which have obvious environmental and ecological benefits.

(2) Protect the environment and ecological environment of downstream areas

The development and utilization of hydropower resources is an important part of the comprehensive utilization of water resources. The construction of large and medium-sized water conservancy and hydropower projects has multiple functions such as flood control, power generation, shipping, water supply, and irrigation. Reservoirs have storage capacity, which has changed the uneven distribution of inter-annual and intra-annual runoff under the river's natural state. Reservoirs can effectively block floods, significantly reduce the damage to the environment and ecology of downstream areas caused by flood disasters, and help protect the environment and ecology.

(3) Improve the environment and ecology of the reservoir area

The reservoir has formed a relatively large artificial lake. When the evaporation capacity increases, the solar radiation heat would be adjusted, causing local microclimate changes in the reservoir area and adjacent areas. The temperature rises in winter decreases in summer, and the humidity increases. The atmosphere around the reservoir becomes relatively humid, conducive to the growth of crops, economic crops, and afforestation and can improve and restore the environment and ecology. The reservoir has formed a new landscape ecological system, creating a better habitat for birds and amphibians. Therefore, the development and utilization of hydropower resources will help improve the reservoir and surrounding areas' environment and ecology.

\subsubsection{Disadvantages of hydropower}

(1) Biology

Dams block the river, change the environment of aquatic organisms, and then harm aquatic animals.

(2) The river

Reservoirs have lower dilution and self-purification capabilities than natural rivers. The water quality of the water body changes in terms of organic matter, heavy 
metals, and nutrients. If pollution sources are not treated, water pollution will affect people's health. When the reservoir is put into operation, the water and sand conditions of the natural river would be changed. When the sediment-carrying capacity of the river downstream of the dam is unsaturated, the riverbed would be scoured and cause beach changes, and adversely affect the downstream dikes and bank buildings.

(3) Areas around the river

The dam controls the silt lost in upstream, and a large amount of silt affects the regulation capacity of the reservoir and affects the navigation of rivers. Furthermore, the reservoir will inundate natural landscapes such as rapids, canyons, special karst landforms, and some cultural relics and rare plants in natural rivers.

(4) Engineering to environment

Large and medium-sized water conservancy and hydropower projects have characteristics of many buildings, large engineering volumes, long construction periods, a large number of construction machinery and equipment, high mechanization, and high construction intensity, which have adverse effects on the environment [11].

\subsubsection{Rationality}

Hydropower is a clean, renewable, and pollution-free energy, with low operating costs. It can greatly reduce the emission of $\mathrm{SO} 2, \mathrm{CO} 2$, airborne particles, fly ash, and other pollutants. China ranks first in the world in terms of hydropower resources and potential hydropower resources. Currently, the total installed hydropower capacity in China has exceeded 150 million $\mathrm{kW}$, and the utilization rate of hydropower energy development has increased from less than $10 \%$ before the reform and rising to nearly $30 \%$. The rapid development of the hydropower industry has made important contributions to the national economy and social development, and at the same time, promoted the prosperity of China's power equipment manufacturing industry [12].

\subsection{Nuclear energy}

Because of its low-carbon and high-efficiency characteristics, nuclear power generation has become the focus of research worldwide. Research on nuclear power in China started late, but the technology in this field has developed rapidly in recent years. The number of nuclear power plants in operation and the total installed nuclear power capacity in China ranks fourth globally. From January to December 2019, the cumulative power generation of China's 47 operating nuclear power units (excluding Taiwan's nuclear power information) was 348.131 billion $\mathrm{kWh}$, accounting for approximately $4.88 \%$ of China's cumulative power generation.

\subsubsection{Principles of Nuclear Power}

Nuclear power generation uses the heat released by nuclear fission in a nuclear reactor to generate electricity. The energy of nuclear power generation comes from the fission energy released by the fission reaction of the fissionable material (nuclear fuel) in the nuclear reactor, which is the energy released from the nucleus by converting its mass. At present, most nuclear power plants in the world adopt light water reactor types. Light water reactors are divided into pressurized water reactors and boiling water reactors. China's nuclear power plants are mainly pressurized water reactors [13].

\subsubsection{Advantages of nuclear power generation}

(1) Environmental protection

Nuclear power generation is different from thermal power generation. It does not require fuel storage, waste slag sites, etc. It does not directly produce SO2, NOx, mercury, or other pollutants related to fossil fuels' combustion, nor does it directly produce $\mathrm{CO} 2$. It is a clean energy source.

(2) Economy

Nuclear energy is a highly enriched energy source. The energy produced by the fission of 1 ton of uranium is equivalent to 2.4 million tons of standard coal. Therefore, the fuel used by nuclear power plants is small and convenient for transportation and storage.

(3) Security

After decades of development and improvement, nuclear power plants have become one of the safest sectors. The safety record of China's nuclear industry for many years is good proof. Nuclear reactors in nuclear power plants use fissile materials as fuel. This fuel is scattered inside the reactor and will not explode like an atomic bomb under any circumstances. Even if external factors destroy the reactor, the reactor will only return to its original state and stop automatically, and there will never explode. Now the International Atomic Energy Agency and the national security departments of various countries have established a series of safety regulations and guidelines to strictly manage the safety of nuclear power plants.

\subsubsection{Disadvantages of nuclear power generation}

(1) Thermal pollution

Due to the low efficiency of nuclear power plants, the waste heat released by nuclear power plants for every 1 $\mathrm{kW}$ of generated electricity is $40 \%$ more than that of coalfired power plants of the same level. This waste heat must be transferred to the environment. If water cooling is used, the total amount of water required is astonishing. The cooling water volume of a $1000 \mathrm{MW}$ nuclear power plant is $28400 \mathrm{~L} / \mathrm{s}$, and the water temperature is usually raised to $100{ }^{\circ} \mathrm{C}$. There may be various chemical and biological effects on the environment.

(2) Radioactive pollution

During the nuclear reaction of nuclear power plants, radioactive fission and activation products will be produced, some of which enter the environment through gaseous pathways. These radioactive effluents will change the local water radioactivity level, produce radiation doses to aquatic organisms, and may also affect the use of surrounding freshwater resources. Besides, a certain 
amount of chemical reagents must be added during the operation of a nuclear power plant to meet system operation requirements. Therefore, the liquid effluent of a nuclear power plant contains a certain amount of chemical pollutants in addition to radionuclides [14].

\subsubsection{Rationality}

According to data recently released by the China Nuclear Energy Industry Association, from January to June 2016, China's cumulative power generation was 2,759,490 million $\mathrm{kWh}$, and the commercial nuclear power unit's cumulative power generation was 95.389 billion $\mathrm{kWh}$, accounting for approximately $3.46 \%$ of the country's cumulative power generation. Compared with the world level, this ratio is still low. Compared with coal-fired power generation, nuclear power generation is equivalent to reducing the $30,047,500$ tons burning standard coal, reducing 78,724,500 tons $\mathrm{CO} 2$ emissions, reducing 255,400 tons sulfur dioxide emissions, and reducing 222,400 tons nitrogen oxide emissions. It can also be seen that China's nuclear power generation technology is becoming more and more mature. Because energy shortage has become an important factor restricting the sustainable development of the economy, nuclear power generation is the main means to solve China's energy crisis.

\subsection{Biomass energy}

\subsubsection{Classification of biomass energy resources}

There are many biomass resources in life, and they can be divided into different types of biomass resources: forest resources, crop straws, poultry manure, and household garbage, according to different classification standards

Forest resources are biomass energy provided by forest growth and forestry production processes, mainly fuelwood, and some industrial wood residues. Forest resources account for a large proportion of China's energy resources.

Crop straws mainly include the stems, leaves, and roots of crops. China is a large agricultural country with abundant agricultural resources. When the crop straw is processed and then used, it can improve combustion efficiency and avoid waste. Therefore, crop straw is also an important source of biomass energy.

Poultry manure is the general term for livestock and poultry excrement. It is the transformation form of other biomass forms (mainly grain, crop straw, and pasture, etc.), including manure, urine, and bedding mixture from livestock and poultry. The use of concentrated scientific treatment can make better use of livestock manure.

Domestic waste mainly refers to waste generated by urban residents, life, services, etc. With the improvement of people's living standards, more and more garbage is generated in life. If these garbage are buried or burned, it will have a great impact on the environment. Now the garbage is classified and processed into biomass energy for reuse, which protects the environment and solves social problems [15].

\subsubsection{Biomass Energy Conversion Technology}

According to the different humidity of raw materials, biomass energy can be divided into two categories: dry biomass and wet biomass. Generally, dry organisms can be converted into biomass energy by direct combustion, thermochemical and physicochemical methods. Wet organisms can be converted into biomass energy by biotechnology and chemical methods. Biological resources can be transformed into solid, liquid, and gaseous fuels by the above methods [16].

\subsubsection{Direct combustion method}

The direct combustion method's treatment process is simple and easy to operate, but if the combustion is not sufficient, it will cause certain damage to the environment. In the past, people mainly used stoves and boilers for combustion treatment. Later, the solid molding combustion method gradually replaced the previous combustion method. Solid molding combustion refers to the conversion of the organism after solidification treatment, which improves the conversion efficiency, enables the organism to burn fully and rationally utilizes resources, and reduces the emissions of $\mathrm{CO} 2$ and sulfur dioxide and protects the environment.

\subsubsection{Materialization conversion method}

Physicochemical conversion mainly includes three methods of liquefaction, gasification, and thermal degradation of organisms. People can convert organisms into biomass energy through physicochemical conversion. Liquefaction refers to the process of transforming organisms into liquid form through chemical reactions. The essence of liquefaction is the process of turning solid substances of large molecules into organic substances of small molecules under certain conditions, including indirect liquefaction and direct liquefaction. Biomass gasification refers to the process of heating the organisms to break the bonds of macromolecular solid substances and produce carbon monoxide, methane, hydrogen, and other gases under the condition of incomplete combustion. Bio-thermal degradation refers to drying the organism, grinding and pulverizing, putting the ground slag into the reactor, passing sulfide gas and heating it at high temperature to fully burn it into the form of charcoal, and then Collect after cooling.

\subsubsection{Biochemical transformation technology}

Biochemical conversion mainly includes anaerobic digestion to produce biogas and enzymatic technology to produce ethanol or methanol liquid fuel. Biogas production technology by anaerobic digestion refers to the process of placing the organic matter in an anaerobic environment and converting it into biogas through the interaction of microorganisms. The anaerobic digestion process is essentially the process of biogas fermentation, and the whole process is very complicated. Enzyme technology to produce ethanol or methanol technology is 
the most important extraction of methanol and ethanol. Usually, ethanol can be effectively extracted from plants.

\subsubsection{Chemical transformation method}

The chemical conversion method refers to the reaction according to the corresponding chemical formula to produce different biomass energy, such as biodiesel. There are mainly three production methods: physical, chemical, and biological. The physical method includes the direct mixing and the microemulsion ones; the chemical method includes the cleavage, the transesterification, and the esterification ones; the biological method mainly refers to the bio-enzyme catalyst synthesis of biodiesel technology.

\subsubsection{Advantages and disadvantages of biomass energy}

\section{(1) Renewability}

The biggest feature of biomass energy is its renewability. Biomass energy is obtained by converting solar energy, and solar energy is an inexhaustible natural resource. Therefore, biomass energy is the same renewable energy as tidal and wind energy, achieving long-term and sustainable development.

(2) Rich resources

As a country with a large population and agriculture globally, my country has abundant resources available in the development of material energy. According to relevant statistics, the energy that can be converted from biomass in my country each year is equivalent to the energy of 500 million tons of standard coal. Moreover, there are abundant sources of biomass energy. So far, more than a dozen kinds of raw materials can be used for the development and utilization of biomass energy.

(3) Less environmental pollution

Biomass contains less sulfur and nitrogen and produces less harmful gases $\mathrm{SO} 2$ and NOx after combustion. Also, the amount of $\mathrm{CO} 2$ emissions from biomass is very small during the utilization process, which has a significant effect on mitigating the greenhouse effect.

(4) Alternative advantages

Based on current research, biomass energy can be converted into biomass molding fuel, combustible biomass gas, and biomass liquid fuel, which could replace the fossil energy.

\subsubsection{Disadvantages of biomass energy}

(1) The market environment and guarantee mechanism are not perfect

China's biomass energy development lacks clear strategic goals and does not have a complete market system. It is still in the stage of "production-based sales and planned supply".

(2) Difficult to commercialize

The scattered resources, backward collection methods, and slow industrialization process restrict the large-scale and commercial utilization of biomass energy high-tech. Centralized power generation and heating are the main technical methods for efficient and clean utilization of biomass energy in the world. However, these technologies need to have a certain scale to produce economic benefits.

(3) Backward technology

At present, China has not yet reached a mature level in new energy research and development and is still in the exploratory stage. Compared with a developed country, China's biomass energy technology is relatively backward.

(4) Utilization restrictions

Some problems restricting biomass power generation have gradually emerged. The low electricity price subsidy standard makes biomass power generation projects face losses once they are put into operation [17].

\subsubsection{Prospect analysis of China's development of biomass energy industry}

China is a large agricultural country with 6.7 million square kilometers of agricultural land and forest land, which has brought huge development potential to China's biomass energy development. Biomass energy can replace fossil fuels to a certain extent and realize non-renewable resources. Compared with Western developed countries, China has abundant labor resources. Automation technology gradually matures, and economic benefits gradually become prominent. Although China's biomass energy industry is still in a stage of steady development, nowadays, with the help of artificial intelligence, mechanical automation, and other technologies, China's biomass energy technology has gradually matured. In the future, the biomass energy industry's economic benefits will become more prominent, and it is an important measure to realize the sustainable development of the human economy and society [18].

\section{Carbon capture and carbon storage}

\subsection{Carbon capture}

\subsubsection{Comparison of carbon capture technologies}

At present, the mainstream technologies for carbon capture include chemical absorption, physical absorption, adsorption separation, and membrane separation. These technologies have obvious differences in processes, equipment, energy consumption, and products (see Table 2 ). Among them, the chemical absorption method has mature technology and is the most widely used technology [19].

\subsubsection{Research on CO2 capture methods}

\subsubsection{Chemical absorption method}

The chemical absorption method mainly uses the chemical reaction between $\mathrm{CO} 2$ and certain solvents to capture $\mathrm{CO} 2$, then decompose the material to separate the $\mathrm{CO} 2$, and finally achieve the purpose of purifying $\mathrm{CO} 2$. Its capture 
efficiency and energy consumption are relatively high [20].

\subsubsection{Physical absorption method}

The physical absorption method mainly relies on the solvent's dissolving ability to capture $\mathrm{CO} 2$. There is no chemical reaction in this process. The capture method has the advantages of high capture efficiency and less solvent consumption. When the partial pressure of $\mathrm{CO} 2$ is relatively large, this method can be applied.

\subsubsection{Pressure swing adsorption method}

The pressure swing adsorption method mainly relies on van der Waals forces between substances to selectively adsorb $\mathrm{CO} 2$, and then release the captured $\mathrm{CO} 2$ by reducing the pressure or increasing the temperature, and finally achieve the purpose of $\mathrm{CO} 2$ separation. The application cost of this method is relatively high. This method has been widely used in the gas separation work of industrial production in China. At present, the common adsorption materials are molecular sieves and zeolites. The research and development of high-performance nonpolluting adsorption materials is a problem facing this field.

\subsubsection{Membrane separation method}

The so-called membrane separation method is mainly based on the sieve effect of the gas. Different molecules and materials will produce different thermal and dynamic effects. According to this principle and method, $\mathrm{CO} 2$ can be effectively adsorbed from the mixed gas. This method has relatively strong stability and relatively simple operation, but the cost of membrane materials is relatively high, and the absorption efficiency is relatively low. The development of low-cost and high-performance membrane materials is the application of membrane separation methods.

Table 2. Comparison of mainstream carbon capture technologies

\begin{tabular}{|c|c|c|l|l|}
\hline Technology & $\begin{array}{c}\text { CO2 } \\
\text { purity/\% }\end{array}$ & $\begin{array}{c}\text { Core } \\
\text { material }\end{array}$ & \multicolumn{1}{|c|}{ Advantages } & \multicolumn{1}{c|}{ Disadvantages } \\
\hline $\begin{array}{c}\text { Chemical } \\
\text { absorption }\end{array}$ & 99 & Absorbent & $\begin{array}{l}\text { Good flue gas adaptability; mature } \\
\text { technology; suitable for large-scale and } \\
\text { low-concentration CO2 capture in power } \\
\text { plant and cement plant }\end{array}$ & $\begin{array}{l}\text { High investment cost; high energy } \\
\text { consumption: energy consumption for } \\
\text { absorbent regeneration2.5 } \sim 4 \mathrm{GJ} / \mathrm{t} \text {; high } \\
\text { operating cost: 300 400 yuan/t; strong } \\
\text { corrosiveness }\end{array}$ \\
\hline $\begin{array}{c}\text { Physical } \\
\text { absorption }\end{array}$ & 98 & Absorbent & $\begin{array}{l}\text { CO2 concentration and low heavy } \\
\text { hydrocarbon content; non-corrosive } \\
\text { solvent; relatively low energy } \\
\text { consumption }\end{array}$ & $\begin{array}{l}\text { Limited trapping capacity, not suitable } \\
\text { for independent use, can be used in } \\
\text { conjunction with chemical absorbents or } \\
\text { adsorption materials; require high- } \\
\text { pressure conditions }\end{array}$ \\
\hline $\begin{array}{c}\text { Pressure } \\
\text { swing } \\
\text { adsorption }\end{array}$ & 97 & Adsorbent & $\begin{array}{l}\text { Relatively low energy consumption; } \\
\text { simple process; no secondary pollution }\end{array}$ & $\begin{array}{l}\text { Low purity of the separated CO2; } \\
\text { obvious pressure drop of the whole } \\
\text { system }\end{array}$ \\
\hline $\begin{array}{c}\text { Membrane } \\
\text { separation }\end{array}$ & 97 & $\begin{array}{c}\text { Membrane } \\
\text { material }\end{array}$ & $\begin{array}{l}\text { Low energy consumption; small } \\
\text { equipment size, simple operation, and } \\
\text { maintenance; strong compatibility }\end{array}$ & $\begin{array}{l}\text { The short life of the separation } \\
\text { membrane leads to high total cost; poor } \\
\text { adaptability to flue gas; poor antifouling } \\
\text { ability of the membrane }\end{array}$ \\
\hline
\end{tabular}

\subsection{Carbon storage}

\subsubsection{Geological storage}

\subsubsection{Geological storage methods}

Geological storage is a method of permanently and effectively storing $\mathrm{CO} 2$ gas. The $\mathrm{CO} 2$ in a supercritical state is injected into the closed geological structures such as oil-bearing, gas-bearing, water-bearing, or noncommercial coal seams through pipeline technology to form long-term or permanent The storage of $\mathrm{CO} 2$ on the ground is widely regarded as the primary choice for $\mathrm{CO} 2$ storage.

\subsubsection{Abandoned mines and non-minable coal seams for storage}

Coal seams with no commercial value or unmineable coal can also be used as long-term $\mathrm{CO} 2$ storage sites. Injecting $\mathrm{CO} 2$ into the coal seam could improve the recovery rate of coalbed methane (ECBM), and then $\mathrm{CO} 2$ diffuses in the pores and cracks of the coal seam and is adsorbed by the coal. The adsorption capacity of coal for $\mathrm{CO} 2$ is about twice that of methane. Therefore, $\mathrm{CO} 2$ can be used to displace the methane in the coal seam and change the methane from the adsorption state to the free state, which 
not only realizes the utilization of coal bed methane but also realizes the storage of $\mathrm{CO} 2$.

\subsubsection{Carbonization and storage of minerals}

The carbonization reaction can absorb $\mathrm{CO} 2$ on a large scale, a potential storage method that can accelerate the geological weathering process. Mineral storage is the use of minerals to react with $\mathrm{CO} 2$ in the process of carbonization:

$$
\mathrm{MgO}+\mathrm{CO} 2-\mathrm{MgCO} 3+\text { heat }
$$

Calcium or magnesium oxides are ideal targets for carbonization reactions because the produced carbonates $(\mathrm{CaCO} 3, \mathrm{MgCO} 3)$ are not easily soluble in water and can be used as backfills in open-pit coal mines or suitable for coal mining. The method of mineral storage involves waste treatment and large-scale mining. Alkaline waste in industrial processes can become raw materials for mineral carbonization. For example, municipal waste incineration, coal combustion, and ash from cement production have good potential. Raw materials, while reusing waste materials, make it produce higher economic value.

\subsubsection{Marine storage}

The amount of carbon stored in the ocean far exceeds that of the atmosphere, making the ocean an optimal storage location for the captured $\mathrm{CO} 2$. The ocean's surface water exchanges $\mathrm{CO} 2$ with the atmosphere within a time frame of several months to several years, so a deeper sea area must be selected for storage. Ocean storage requires the use of pipelines or ship transportation to transport supercritical CO2 fluid to the deep sea or the deep sea bed. The first method is to melt the supercritical CO2 fluid into the deep seawater. The second method: if the injection depth exceeds $3000 \mathrm{~m}$ (the critical depth of $\mathrm{CO} 2$ suspending force in seawater) and the location is a depression seabed, $\mathrm{CO} 2$ can form a supercritical fluid lake for long-term storage.

There are still a lot of problems in ocean storage that need to be solved. The injection of a large amount of $\mathrm{CO} 2$ into the seawater will cause acidification of the seawater and destroy the ocean's ecological environment. Although the potential of ocean storage of $\mathrm{CO} 2$ is enormous, ocean storage is still undergoing many experiments due to the complexity and coordination of the ocean system. Furthermore, it is difficult for existing technologies and methods to monitor it effectively for a long time.

\subsubsection{Saline-alkali aquifer storage}

The storage of saline-alkali aquifers has the advantages of being close to the capture site, simplifying transportation methods, and saving costs. Furthermore, the possibility of good penetration in saline-alkali aquifers is far less than that of oil and gas reservoirs. Therefore, saline-alkali aquifers' storage potential is much higher than the storage potential of oil or gas reservoirs.

\subsubsection{Storage of terrestrial ecosystems}

Terrestrial ecosystem storage uses forests, wetlands, and grasslands to "capture" carbon-free in the atmosphere through photosynthesis so that plants can form organic compounds. Part of the production will be consumed and returned to the atmosphere in the form of $\mathrm{CO} 2$, while the other part of the product will exist for a longer time in the form of biomass and soil carbon stock [21].

\subsubsection{Current status of geological storage research}

The mechanism of multiphase flow and migration of supercritical pressure $\mathrm{CO} 2$ and water in the reservoir's porous structure are the key issues in the long-term safe storage of $\mathrm{CO} 2$ and efficient geological utilization. However, the changes in pore surface wettability, pore structure, and reservoir pressure may occur with the longterm $\mathrm{CO} 2$ storage process. So it is impossible to predict the long-term safety of storage [22].

\section{Conclusion}

This article reviews the ways of reducing carbon emissions from new energy sources, carbon capture, and storage.

New energy sources include wind energy, solar energy, hydropower, nuclear energy, and biomass energy. Generally speaking, the biggest feature of new energy is green and low pollution. Among them, the cost of wind energy utilization is low, but the wind is unstable. However, its power generation technology is immature and has certain damage to the environment. Solar energy is sufficient, universal, and easy to obtain, but solar energy is low in density, intermittent, unstable, and high in utilization costs. China is rich in solar energy resources, and the solar power industry has a broad prospect. Hydropower is a kind of renewable energy, which is mainly used for hydroelectric power generation. Nuclear energy is economically safe, but it will produce thermal and radiation pollution. China's nuclear power generation technology is becoming more and more maturer. Biomass energy resources are abundant, but it is difficult for commercial development as technology is backward. China's biomass energy technology is gradually mature, and biomass energy is an important way to realize the human economy and society's sustainable development.

Carbon capture and carbon storage technology is one of the more effective and potential technologies to solve global warming in the future. Common carbon capture technologies include chemical and physical absorption methods, adsorption separation methods, membrane separation methods, and biological carbon sequestration methods. Geological storage is a method of permanently and effectively storing $\mathrm{CO} 2$ gas. Injecting $\mathrm{CO} 2$ under supercritical conditions into closed geological structures through pipeline technology is widely regarded as the first choice for $\mathrm{CO} 2$ storage. 


\section{References}

1. Z. Lun, Journal of China Institute of Environmental Management, Summary of Research on Greenhouse Effect (1996)

2. Q. Yuchun, D. Yunshe, Geographical Sciences, Research on the Current Status of Greenhouse Gas Emissions in China's Energy Sector and Countermeasures for Emission Reduction [J] (2004)

3. Z. Fei, Research on China's carbon emission trading legal system (2010)

4. Z. Guowei, G. Guangcai, W. Zhi, Energy Saving Technology (2007)

5. D. Junhu, Y. Lei, Introduction to Research on Greenhouse Effect and Global Warming (2001)

6. Y. Lei, Applied Energy Technology, Analysis on the sustainable development of wind power generation [J] (2007)

7. Y. Yuechun, The status quo, development prospects and market of wind power generation [J] (2014)

8. J. Qiuling, Z. Liang, W. Di, G. Kai, Shanxi Architecture, Research on the Application and Development of Solar Green Energy (2020)

9. Y. Yunfei, Z. Zhien, Z. Li, D. Changlin, Acta Solar Energy, Solar energy utilization technology and its application (2012).

10. Y. Fengkai, Earth, On the development and utilization of clean energy-solar energy (2015)

11. W. Shucheng, Hydropower, On dams and ecology (2004)

12. L. Jiajun, Building Engineering Technology and Design, Talking about the principles and advantages of hydropower [J] (2017)
13. G. Genzhi, Z. Xiaoqiong, J Jianping, Hydropower and New Energy, Nuclear Power Generation Technology (2012)

14. C. Guoyun, F. Duping, Electric Power Technology and Environmental Protection, The characteristics and prospects of nuclear power generation, 27(5), 48-50 (2011)

15. X. Yang, L. Haifeng, L. Na, Hubei Agricultural Mechanization, Development and utilization of biomass energy [J], 44-45 (2020)

16. L. Shuyang, Comprehensive Utilization of Resources in China, Research on Biomass Energy Conversion Technology and Comprehensive Development and Utilization of Resources[J], 35(10), 46-47+71 (2017)

17. X. Yang, L. Haifeng, L. Na, Hubei Agricultural Mechanization, Development and utilization of biomass energy[J], 2020(09), 44-45 (2020)

18. J. Yaohua, Economic Research Guide, Research on the development prospects of my country's biomass energy industry[J], 2020(25), 44-45 (2020)

19. X. Yi, C. Yanyan, L. Wenhao, W. Di, L. Gang, G. Yuanbo, Petrochemical Technology and Application, Application progress of carbon capture technology and carbon trading market analysis $[J], \mathbf{3 8 ( 0 5 )}, 353-$ 357 (2020)

20. W. Gaoxiang, T. Rui, Yunnan Chemical Industry, Research progress of carbon dioxide capture technology [J], 47(04), 22-23 (2020)

21. X. Bo, L. Yong, W. Shen, Y. Shuai, W. Yuyang, World of Chemistry, Carbon capture, storage and utilization technology and coal seam storage CO_2 research progress [J], 61(04), 294-297 (2020)

22. X. Ruina, J. Peixue, China Basic Science, Research progress of $\mathrm{CO}_{2} 2$ geological storage and utilization technology[J], 20(04),44-48 (2018) 